\title{
DERECHO Y FACTOR RELIGIOSO EN CHILE Y EN EL PERÚ. ¿HACIA LA GESTIÓN PÚBLICA DE LA DIVERSIDAD RELIGIOSA?
}

\author{
LAW AND RELIGIOUS FACTOR IN CHILE AND PERU TOWARDS THE \\ PUBLIC MANAGEMENT OF RELIGIOUS DIVERSITY
}

\author{
Miguel SÁNCHEZ-LaSHERAS ${ }^{*}, *$
}

RESUMEN: En este artículo se efectúa un análisis comparado y actual de la regulación del factor religioso en Chile y en el Perú. Si bien cada país ha tenido su propia evolución histórica, en la actualidad ambos tutelan este derecho fundamental y, de una u otra forma, prevén mecanismos de colaboración entre el Estado y las confesiones religiosas. A juicio del autor, existe la posibilidad de desarrollar un Derecho bilateral o pacticio donde se conjugue la laicidad del Estado con el reconocimiento de la vitalidad del hecho religioso como factor social, tal y como ha sucedido en algunos países europeos (España, Italia y Alemania, entre otros). No en vano, la existencia de sociedades cada vez más diversas e interculturales demanda una flexibilización de las normas jurídicas y una posición sestatal garante de los derechos y de las libertades públicas.

Palabras clave: Pluralidad religiosa, laicidad, cooperación Estado-confesiones religiosas, derecho comparado.

ABSTRACT: This article makes a comparative analysis of the regulation of religious freedom in Chile and Peru. Although each of these countries has had its own historical evolution, currently both of them protect this fundamental right and, one way or another, provide mechanisms for collaboration between the State and religious denominations. The author notes that some European countries have developed a bilateral law which intends to combine the secular state with the recognition of the vitality of religion as a social factor. In his view, the existence of increasingly diverse and intercultural societies demand more flexible laws and states that guarantee the protection of civil rights and civil liberties.

Key words: Religious diversity, secular state, cooperation with religious denominations, comparative law.

\footnotetext{
Doctor Europeo en Derecho por la Universidad de Navarra (España). Profesor asociado de Historia del Derecho y de Derecho Canónico de la Pontificia Universidad Católica de Valparaíso. Dirección Postal: Avenida Brasil 2950, segundo piso, Valparaíso. Correo electrónico: miguel.sanchez@ucv.cl

** El presente trabajo se basa, en parte, en el contenido de mi comunicación "La desaparición de la confesionalidad del Estado en Chile y en el Perú", presentada en las IV Jornadas Chileno-Peruanas de Historia del Derecho (Valparaíso, 29 y 30 de mayo de 2014); de ahí que se haga un análisis comparado entre el Perú y Chile. También he incluido y ampliado algunos párrafos de mi ponencia "Los acuerdos entre el Estado y las confesiones religiosas en España: ¿una referencia para Chile?”, dictada en la Jornada Pluralidad Religiosa y Derecho en Chile: hacia acuerdos entre el Estado y las confesiones religiosas (Santiago, 10 de abril de 2015). Me gustaría agradecer la ayuda prestada por los alumnos Ignacio Sánchez y Francisco Costa para la elaboración de este artículo.
} 


\section{INTRODUCCIÓN: DE LA COLONIA A LOS ESTADOS DEL SIGLO XXI}

El factor social religioso ha sido, históricamente, un elemento esencial en la configuración jurídica de las naciones. Los estados latinoamericanos no son una excepción a este fenómeno y, en casi todos ellos, su relación con el hecho religioso -y en concreto, con la Iglesia católica - trae causa de la colonización llevada a cabo por los Reyes de España en virtud del título otorgado por las bulas alejandrinas ${ }^{1}$. De ahí que los procesos de conquista y de evangelización iniciados a finales del siglo XV se estudien de forma conjunta e interdependiente, al constituir dos realidades estrechamente vinculadas entre sí.

En este sentido, no es exagerado afirmar que el celo evangelizador de la Corona española traspasó los límites propios del mandato pontificio, pues "no se trató de una forma más de colaboración entre el poder temporal y el poder espiritual, ni de una protección genérica de la Iglesia por los gobernantes; por el contrario, todo giraba en torno a una tarea que, si bien había sido inicialmente encargada por los Papas a los monarcas hispanos, estos, por propia decisión, no solo la asumieron como suya, sino que la antepusieron a toda otra tarea de orden temporal"2.

Así, desde los orígenes de la colonia existió un indudable maridaje entre las esferas religiosa y política plasmado en la confesionalidad católica del Estado y en la vigencia del llamado "Patronato real de Indias" que otorgaba a los monarcas españoles amplias facultades de intervención en el nombramiento de las autoridades eclesiásticas. Precisamente, el contexto confesional explica el interés de las autoridades políticas por intervenir en la designación de los obispos que iban a ser titulares de las distintas diócesis de los territorios de ultramar ${ }^{3}$.

Por otro lado, la independencia de España alcanzada por la mayoría de las naciones latinoamericanas en el primer tercio del siglo XIX no supuso un cambio significativo en las relaciones del Estado con la Iglesia católica. Al menos en los casos de Chile y de Perú, el reconocimiento constitucional de la libertad religiosa no se produjo hasta bien entrado el siglo XX.

En la actualidad, y a pesar de la indudable y creciente secularización de las sociedades occidentales, los asuntos relacionados con la libertad religiosa siguen precisando de un tratamiento jurídico específico; dicho lo cual no sorprende que existan organismos públicos destinados a proteger y promover este derecho fundamental,, en un momento histórico en que la tutela de los derechos y de las libertades públicas deviene ineludible para los Estados y para la comunidad internacional. Por otra parte, la vigencia en materia religiosa de un

\footnotetext{
1 Se trata de las bien conocidas bulas otorgadas por el Papa Alejandro VI a los Reyes Católicos, a saber: Inter caetera, de 3 y 4 de mayo de 1493; Eximiae devotionis, de 3 de mayo de 1493; y, Eximiae devotionis sinceritas, de 16 de noviembre de 1501. Vid. Salinas (2004) p. 51.

2 Salinas (2004) p. 56.

3 "Las Bulas alejandrinas habían otorgado a la Corona de Castilla el mando político y administrativo de los nuevos territorios al tiempo que ofrecían al monarca amplias competencias en materia espiritual y económica. En esa misma línea el Papa Julio II, ante la insistencia con que la Corona lo solicita, otorga el ansiado Derecho de Patronato a los Reyes de España. Se concede un derecho exclusivo de fundación de establecimientos eclesiásticos, señalando expresamente las ecclesias magnas, y un derecho de presentación a todos los beneficios eclesiásticos y a todos los lugares píos. Los monarcas españoles se convirtieron de facto, en delegados del Pontífice para el gobierno eclesiástico de las Indias" Mosquera (2012) p. 155.
} 
derecho bilateral o pacticio, de génesis consensuada, constituye un signo inequívoco de la trascendencia social y jurídica de los grupos o comunidades de índole religiosa.

En este artículo se ofrece una visión de conjunto - sin pretensiones de exhaustividadde los antecedentes históricos y de la situación actual de la gestión pública de la diversidad religiosa en Chile y en el Perú. Además, se expone cómo podría ser su evolución en un futuro próximo, atendiendo a la praxis vigente en el Derecho comparado.

\section{DERECHO Y FACTOR RELIGIOSO EN EL PERÚ}

\subsection{EVOLUCIÓN DE LA NORMATIVA CONSTITUCIONAL}

Las diversas constituciones vigentes en el Perú durante el siglo XIX y comienzos del siglo XX proclamaron la confesionalidad católica del Estado ${ }^{4}$, prohibiéndose en la mayoría de ellas el ejercicio público de cualquier otro credo religioso ${ }^{5}$. Parece claro que en esta materia el texto constitucional que sirvió como modelo fue la Constitución española de 1812, que en su artículo 12 establecía una confesionalidad excluyente: "la religión de la nación española es y será perpetuamente la católica, apostólica y romana, única verdadera. La nación la protege por las leyes sabias y justas, y prohíbe el ejercicio de cualquier otra"6.

Así, los primeros textos legislativos promulgados en el Perú ya independizado omiten toda alusión a la libertad de cultos y confirman la vigencia de una confesionalidad que podríamos calificar de cerrada ${ }^{7}$. El artículo 8 de la Constitución de 1823 prácticamente reproduce el tenor literal del texto español de 1812, y en el artículo 9 se alude a la religión católica prescribiendo que era "un deber de la nación protegerla constantemente, por todos los medios conformes al espíritu del evangelio, y de cualquier habitante del Estado respetarla inviolablemente" 8 .

Cabe advertir que la prohibición de cualquier manifestación religiosa distinta de la católica fue una constante en el siglo XIX, con la excepción de lo dispuesto en la Carta Magna de 1826, cuyo artículo 6 establecía que la religión del Perú era la católica, apostólica y romana, pero sin exclusión de las demás ${ }^{9}$. Avanzado ya el siglo XX, fue la Carta Magna de

\footnotetext{
${ }^{4}$ Se trata de las constituciones de 1823,1826,1828,1839,1856, 1860 y 1920. Para consultar el texto íntegro de las leyes fundamentales que han estado vigentes en el Perú desde su nacimiento como Estado independiente hasta la actualidad, vid. http://www.leyes.congreso.gob.pe/constituciones.html. Página consultada el 3 de septiembre de 2015.

A este respecto, puede verse el estudio de Mosquera (2012).

5 Es el caso de los textos constitucionales citados, con excepción de los promulgados en 1826 y en 1920.

${ }^{6}$ Art. 12 de la Constitución de Cádiz de 1812, disponible en http://www.congreso.es/portal/page/portal/Congreso/Congreso/Hist_Normas/ConstEsp1812_1978/Const1812. Página consultada el 27 de agosto de 2015.

Recuérdese, a este respecto, que la citada carta magna regía también en Chile y en el Perú, al no haberse alcanzado todavía la independencia de la Corona española.

7 Vid. el Reglamento Provisional de Huaura, el Estatuto Provisional y la Ley de Bases dictados por José de San Martín en 1821, citados en CARPIO (1999) pp. 39-41.

8 Artículo 9 de la Constitución de 1823.

9 Vid. art. 6 de la Constitución de 1826. Además, el ideal de la tolerancia religiosa motivó que en 1915 se suprimiera el artículo 4 de la Constitución de 1860, que excluía a los cultos no católicos. Vid. CarPIO (1999) p. 62. Y en 1920 se aprobó una nueva ley fundamental, cuyo artículo 5 consagraba la confesionalidad del Estado pero sin prever cláusulas limitativas para otras religiones
} 
1933 la encargada de introducir un cambio relevante en la materia que nos ocupa, al omitir, por primera vez, toda declaración confesional y reconocer la libertad de cultos mediante la siguiente fórmula: "la libertad de conciencia y de creencia es inviolable. Nadie será perseguido por razón de sus ideas" ${ }^{10}$.

Al mismo tiempo, se consignaba en el texto constitucional el compromiso de los poderes públicos de proteger la religión católica, al ser la mayoritaria en el país ${ }^{11}$. Si bien es discutible la necesidad de incluir dicha cláusula en la constitución, parece obvio que existe un cambio cualitativo en el posicionamiento del Estado ante el factor social religioso: no se adhiere ya a ninguna confesión en particular, sino que se limita a reconocer un hecho sociológico que hunde sus raíces en la historia y en la génesis misma del Estado peruano. Cuestión distinta es determinar, en la práctica, el significado del término proteger aplicado a la religión católica ${ }^{12}$.

La Constitución de 1979 mantuvo la no confesionalidad del Estado, precisamente en un momento histórico en el que, la propia Iglesia católica había solicitado a los estados el reconocimiento de la libertad religiosa como derecho basado en la dignidad humana ${ }^{13}$. De hecho, el Concilio Vaticano (1962-1965) explicitó los principios que debían guiar las relaciones entre los poderes públicos y la comunidad eclesial, a saber: autonomía e independencia recíprocas y mutua cooperación ${ }^{14}$.

En este sentido, no parece aventurado inferir que el constituyente peruano tomó como referencia el modelo típico de los sistemas democráticos más avanzados que, como se ha visto, estaba en sintonía con la nueva propuesta de relación bilateral impulsada por la Iglesia católica. En este contexto de respeto mutuo se negoció el artículo 86 de la Carta Magna de 1979, cuyo tenor literal quedó redactado así: "dentro de un régimen de independencia y autonomía, el Estado reconoce a la Iglesia Católica como elemento importante en la formación histórica, cultural y moral del Perú. Le presta su colaboración. El Estado puede también establecer formas de colaboración con otras confesiones" ${ }^{15}$.

\footnotetext{
10 Art. 59 de la Constitución de 1933.

11 Art. 232 de la Constitución de 1933: «Respetando los sentimientos de la mayoría nacional, el Estado protege la Religión Católica, Apostólica, Romana».

12 La Real Academia de la Lengua Española señala que proteger significa amparar, favorecer, defender (http:// lema.rae.es/drae/?val=proteger, consultada el 27 de agosto de 2015).

Sin embargo, se hace necesario conocer el contexto histórico y la mens legislatoris para entender los alcances que el constituyente peruano otorgaba al deber de protección de la religión católica. En este sentido, vid. INTERDONATO (1981) pp. 89 y 90.

13 Vid. Declaración Dignitatis Humanae del Concilio Vaticano II, disponible en http://www.vatican.va/archive/ hist_councils/ii_vatican_council/documents/vat-ii_decl_19651207_dignitatis-humanae_sp.html. Página consultada el 14 de mayo de 2015. El interés de esta declaración conciliar radica en la solemne proclamación del derecho de libertad religiosa como derecho fundamentado en la dignidad humana, lo que supone una novedad respecto a la doctrina de la mera tolerancia religiosa.

14 Núm. 76 de la Declaración Dignitatis Humanae del Concilio Vaticano II: "La comunidad política y la Iglesia son independientes y autónomas, cada una en su propio terreno. Ambas, sin embargo, aunque por diverso título, están al servicio de la vocación personal y social del hombre. Este servicio lo realizarán con tanta mayor eficacia, para bien de todos, cuanto más sana y mejor sea la cooperación entre ellas, habida cuenta de las circunstancias de lugar y tiempo".

15 Artículo 86 de la Constitución de 1979.
} 
Al ser este artículo prácticamente idéntico a su equivalente en la Constitución de 1993 en vigencia, analizaré ambos en el siguiente epígrafe, dedicado al sistema actual de relaciones entre el Estado y las confesiones religiosas en el Perú.

\section{2. Situación actual en materia de libertad Religiosa}

\subsubsection{Marco constitucional y ley de libertad religiosa}

La Constitución actualmente vigente en el Perú fue promulgada en 1993. De igual manera que en los textos constitucionales de 1933 y 1979, el Estado se declara neutral ante el fenómeno religioso; es decir, no rige la confesionalidad católica y sí la libertad de cultos en términos amplios ${ }^{16}$.

El artículo 50, titulado Estado, Iglesia católica y otras confesiones, prevé la posibilidad de establecer relaciones de cooperación con otros credos, si bien mantiene la alusión nominal a la religión mayoritaria. De hecho, si se compara este artículo con lo dispuesto en la Carta Magna de 1979 se comprueba que el tenor literal es prácticamente idéntico; con una salvedad que, sin embargo, no es baladí: el inciso relativo a que el Estado respeta a las confesiones distintas de la católica ${ }^{17}$.

En este punto, me interesa poner de relieve el reconocimiento formal del papel desempeñado por la religión católica en la formación histórica, cultural y moral del Perú, al estimarse que su influencia en la configuración de la identidad peruana no admite parangón con la de ninguna otra denominación religiosa. Quizá podría efectuarse un paralelismo entre este artículo y la mención explícita a la Iglesia católica recogida en la Constitución española de 1978, que fue incorporada en base a una realidad de hecho similar a la del Perú ${ }^{18}$.

Independientemente de ello, en el Perú -como en España- los poderes públicos deberán velar por la tutela del principio de igualdad en materia religiosa, atendiendo al aporte específico que cada confesión minoritaria pueda realizar. No en vano, entre los objetivos de la vigente ley de libertad religiosa peruana, aprobada en $2010^{19}$, está el de garantizar que la diferenciación en el trato a la religión católica no suponga menoscabo alguno del trato dispensado a los restantes credos. Así se deduce de su artículo 2, cuando prescribe lo siguiente:

${ }_{16}$ Art. 2.3 de la Constitución peruana de 1993: "Toda persona tiene derecho a la libertad de conciencia y de religión, en forma individual o asociada. No hay persecución por razón de ideas o creencias. No hay delito de opinión. El ejercicio público de todas las confesiones es libre, siempre que no ofenda la moral ni altere el orden público".

17 Art. 50 de la Constitución peruana de 1993: "Dentro de un régimen de independencia y autonomía, el Estado reconoce a la Iglesia Católica como elemento importante en la formación histórica, cultural y moral del Perú, y le presta su colaboración. El Estado respeta otras confesiones y puede establecer formas de colaboración con ellas". Sobre los alcances del principio de cooperación en el Perú, vid. PatiÑo (2011) pp. 359-387.

18 "Ninguna confesión tendrá carácter estatal. Los poderes públicos tendrán en cuenta las creencias religiosas de la sociedad española y mantendrán las consiguientes relaciones de cooperación con la Iglesia Católica y las demás confesiones". Artículo 16.3 de la Constitución española de 1978. Disponible en http://www.boe.es/diario_boe/txt.php?id=BOE-A-1978-31229. Página consultada el 14 de mayo de 2015.

19 Ley n ${ }^{\circ} 29635$ de 20 de diciembre de 2010, disponible en http://www2.minedu.gob.pe/digesutp/formacioninicial/wpdescargas/normatividad/ley/Ley_N_29635_libertad_religiosa.pdf. Vid. también su Reglamento de desarrollo (Decreto Supremo No 010-2011-JUS) disponible en http://www.minjus.gob.pe/wp-content/ uploads/2014/03/DS-010-2011-JUS-REGLAMENTO.pdf. Páginas consultadas el 14 de mayo de 2015. 
"toda persona natural es igual ante la ley. Se prohíbe toda acción u omisión que discrimine a una persona en razón de sus creencias religiosas. El Estado reconoce la diversidad de las entidades religiosas. En igualdad de condiciones, gozan de los mismos derechos, obligaciones y beneficios" 20 .

Y todo ello sin perder de vista que la vigencia del principio de igualdad no debería significar, en la práctica, una suerte de uniformidad en el tratamiento de realidades cuantitativa o cualitativamente desiguales. No en vano, la adecuada aplicación del principio de igualdad en materia de libertad religiosa constituye un desafío para los operadores jurídicos, que deben atender a diferentes variables en aras a efectuar una justa ponderación de derechos ${ }^{21}$.

\subsubsection{Referencia a los organismos públicos competentes en materia de libertad religiosa}

En la actualidad, el Ministerio de Justicia y Derechos Humanos del Perú incluye una Dirección General de Justicia y Culto que, entre otros cometidos, se encarga de coordinar las relaciones del poder ejecutivo con la Iglesia católica y con las restantes confesiones ${ }^{22}$. Consta de dos unidades separadas: una para los asuntos relacionados con la religión católica y otra para las materias que conciernen a las demás organizaciones religiosas.

a) Dirección de Asuntos de la Iglesia Católica

Se trata del organismo que sustituyó a la Dirección General de Asuntos Eclesiásticos en el año 2002, y está específicamente dirigido a gestionar las relaciones con una confesión religiosa que es la predominante en el Perú desde su existencia misma como Estado. El tratamiento diferenciado que recibe la religión mayoritaria se fundamenta "en la diversidad de normas legales relativas a aplicarse, ya que la Iglesia católica tiene condición de derecho público, en tanto que las demás confesiones religiosas nacen de los derechos conjugados de libertad religiosa y de asociación, y así pertenecen al ámbito del derecho privado, dentro de un marco de igualdad en los derechos fundamentales y de reconocimiento de las diferencias, por razón de lugar y tiempo"23.

\footnotetext{
20 Art. 2 de la Ley ${ }^{\circ}{ }^{29635}$. Sobre la ley de libertad religiosa peruana, puede verse, entre otros, los siguientes trabajos: Díaz et al. [(coords.) 2014]; GonzÁlez (2013) pp. 15-17; Mosquera (2011) pp. 291-303; y SANTOS (2013).

21 Esta idea se pone de manifiesto en el documento conclusivo del XV Coloquio Anual del Consorcio Latinoamericano de Libertad Religiosa. En él se aduce que, en ocasiones, "la autoridad, en lugar de concentrarse en asegurar que individuos y grupos sean todos titulares y gocen del mismo derecho de libertad religiosa, entiende al principio de igualdad como uniformidad ciega, como igualitarismo matemático, en vez de equilibrio, equidad y justicia, favoreciendo a veces las pretensiones de ciertos grupos minoritarios de eliminar los privilegios de la mayoría en lugar de equiparar a los grupos, extendiendo los beneficios de una al resto, sin privación de beneficios". Conclusiones del XV Coloquio Anual del Consorcio Latinoamericano de Libertad Religiosa, "Avances y Retrocesos en la Protección Jurídica de la Libertad Religiosa", México D. F., 21-23 de mayo de 2015. Disponible en http://www.libertadreligiosa.org/index.php?option=com_content\&view=article\&id=55:conclusiones-xvcoloquio\&catid=22:actividades\&Itemid=15. Página consultada el 31 de agosto de 2015.

22 Vid. http://www.minjus.gob.pe/culto/\#. Página consultada el 31 de agosto de 2015.

23 http://www.minjus.gob.pe/iglesia-catolica/. Página consultada el 28 de agosto de 2015.
} 
La dirección tiene atribuidas una serie de competencias orientadas a garantizar la promoción efectiva de la libertad religiosa, destacándose las siguientes: (i) coordinar acciones tendentes a profundizar en la colaboración del poder ejecutivo con la Iglesia católica; (ii) dictar decretos de reconocimiento de creación o supresión de jurisdicciones eclesiásticas hechas por la Santa Sede; (iii) emitir resoluciones de reconocimiento de nombramientos de autoridades eclesiásticas; (iv) otorgar asignaciones económicas destinadas al clero y a otras personas vinculadas a la Iglesia; (v) legalizar las firmas de las autoridades eclesiásticas en documentos de diversa índole para su uso en el exterior con fines civiles; y, (vi) emitir informes y tramitar la aprobación de donaciones provenientes del exterior destinadas a las jurisdicciones de la Iglesia católica ${ }^{24}$.

\section{b) Dirección de Asuntos Interconfesionales}

Fue constituida en 2002 mediante el mismo decreto que creó la Dirección de Asuntos de la Iglesia católica, en el marco de un Estado garante y promotor de los derechos y libertades fundamentales. Habida cuenta de la relevancia social de las confesiones no católicas en la nación peruana, este organismo se encarga de gestionar todo lo relacionado con su proyección jurídica en el ámbito civil ${ }^{25}$.

Una de las funciones más relevantes de la Dirección de Asuntos Interconfesionales es la gestión del Registro de Entidades Religiosas, que implica la coordinación de los procedimientos evaluadores de las solicitudes de inscripción, así como la actualización de datos y la autenticación de las firmas de las autoridades religiosas correspondientes ${ }^{26}$. La pertinencia de este registro parece fuera de duda, atendido el carácter específico del asociacionismo religioso; si bien cabe advertir que, en ocasiones, no es sencillo discriminar entre las entidades netamente religiosas y las que, aun presentando elementos similares a estas, no reúnen las condiciones necesarias para su inscripción registral. En todo caso, la ley n ${ }^{\circ} 29635$ es clara al determinar que "no se consideran religiosos los fines o actividades relacionados con fenómenos astrofísicos, sicológicos, parasicológicos, adivinación, astrología, espiritismo, difusión de ideas o valores puramente filosóficos, humanísticos, espiritualistas u otro tipo de actividades análogas (...)"27.

Por otra parte, en el artículo 15 se apunta que la inscripción en el Registro de Entidades Religiosas es un requisito necesario para que una confesión religiosa pueda suscribir un acuerdo de cooperación con el Estado ${ }^{28}$. Aunque, hasta el momento, esta posibilidad solo se ha concretado con la Iglesia católica -a través del Acuerdo suscrito entre la San-

\footnotetext{
${ }^{24}$ http://www.minjus.gob.pe/iglesia-catolica/. Página consultada el 28 de agosto de 2015.

25 Vid. http://www.minjus.gob.pe/iglesia-catolica/. Página consultada el 28 de agosto de 2015.

26 Vid. art. 89 D. S. N 026-2002-JUS.

27 Art. 5 párrafo segundo de la Ley n ${ }^{\circ}$ 29635. Por otro lado, el párrafo tercero señala que el Estado debe respetar y garantizar las expresiones religiosas de los pueblos andinos, amazónicos y afroperuanos, así como su derecho de ejercerlas de manera individual o colectiva.

28 "El Estado peruano, en el ámbito nacional, dentro de sus competencias, amparado en el artículo 50 de la Constitución Política del Perú, puede suscribir convenios de colaboración sobre temas de interés común, de carácter legal, con aquellas entidades religiosas que, estando inscritas en el registro a que se refieren los artículos precedentes, hayan adquirido notorio arraigo con dimensión nacional y ofrezcan garantías de estabilidad y permanencia por su número de miembros y actividades".
} 
ta Sede y Perú en $1980^{29}$ - desde el punto de vista jurídico nada impide que en el futuro puedan celebrarse convenios con otras denominaciones religiosas, como ya ha sucedido en varios países europeos.

\section{PLURALIDAD RELIGIOSA Y DERECHO EN CHILE}

\subsection{EVOLUCión DE LA NORMATIVA CONSTITUCIONAL}

Las relaciones entre el poder temporal y el poder espiritual en el Chile independiente vinieron marcadas, al igual que en el Perú, por la confesionalidad católica y patronato heredado de la monarquía indiana ${ }^{30}$. A comienzos del siglo XIX, la independencia de la Corona española no supuso una ruptura en el tratamiento de este asunto; de hecho, las leyes fundamentales chilenas proclamaron una confesionalidad material y no meramente sociológica, que otorgaba a la Iglesia católica una posición de preeminencia en el ámbito civil, sin que cupieran -en la mayor parte de los casos- manifestaciones públicas de otros $\operatorname{credos}^{31}$. Esta coyuntura favoreció la injerencia tanto del poder político en el ámbito religioso como de las autoridades religiosas en asuntos temporales; si bien es cierto que, por lo general, los episodios conflictivos entre ambas partes no revistieron la misma gravedad que en otras naciones latinoamericanas ${ }^{32}$.

Ya en el siglo XX, la Constitución de 1925 posibilitó la apertura hacia un nuevo modelo de relaciones Estado-religión, principalmente a través de la separación de la Iglesia, que llevaba años gestándose ${ }^{33}$. A este respecto, resulta significativa la postura del episcopado chileno, recogida en la "Pastoral colectiva de los obispos de Chile sobre la separación de la Iglesia y el Estado". Si bien no faltaron algunas resistencias iniciales, la supresión de la confesionalidad fue aceptada por la mayoría de los prelados, que estimaban el hecho de que en lo sucesivo la Iglesia pudiera actuar libremente en el ámbito civil, sin prescripciones legales

Los convenios, para ser aprobados como norma legal, deben tener el informe favorable del Ministerio de Justicia y del Ministerio de Economía y Finanzas".

29 Vid. Acuerdo entre la Santa Sede y Perú, de 26 de julio de 1980. Disponible en http://www.vatican.va/ roman_curia/secretariat_state/archivio/documents/rc_seg-st_19800726_santa-sede-peru_sp.html. Página consultada el 14 de mayo de 2015.

30 Sobre la estrecha relación entre el descubrimiento del Nuevo Mundo y su evangelización, vid. FríAs (2007) p. 110. Según el citado autor, en el siglo XVII la Iglesia en América contaba ya con un gran prestigio e influencia entre los criollos. Vid. Frías (2007) pp. 131-133.

31 Vid. la completa sistematización de las diferentes normativas constitucionales realizada en SALINAS (2012a) pp. 212-241.

32 En este sentido, refiriéndose al caso de Chile, afirmaba en 2007 el entonces Secretario de Estado del Vaticano: "En las relaciones entre el Estado y la Iglesia en Chile durante el primer siglo después de la independencia, constatamos que resultó frecuente e incluso habitual la recíproca injerencia de una institución en los asuntos propios de la otra, explicables en parte por las condiciones específicas de la sociedad y de la época que se vivía; sin embargo, ello no condujo sino raramente a situaciones conflictivas. Esto nos revela que Chile contó en sus autoridades civiles y eclesiásticas con hombres capaces de diálogo y que supieron anteponer el bien común a intereses de parte". Conferencia de Tarcisio Bertone titulada "La Iglesia y el Estado a doscientos años de la Independencia nacional. Historia y perspectiva”, dictada en la Pontificia Universidad Católica de Chile el 12 de abril de 2010. Disponible en http://documentos.iglesia.cl/conf/doc_pdf.php?mod=documentos_sini\&id=3978. Página consultada el 13 de mayo de 2015.

33 Vid. art. 10.2 de la Constitución de 1925. 
que interfiriesen en su misión eminentemente espiritual. De hecho, los obispos lamentan las consecuencias negativas de las políticas regalistas en el ejercicio de la misión de la Iglesia, y confían en que el abandono de la confesionalidad católica permitiera iniciar una nueva etapa en el tratamiento jurídico del factor religioso en la nación chilena ${ }^{34}$.

\section{2. Situación actual en materia de libertad Religiosa}

\subsubsection{Marco constitucional y ley de libertad religiosa}

Como es sabido, la religión católica ha sido tradicionalmente mayoritaria en Chile, aunque existen otros credos con una presencia social más o menos notoria ${ }^{35}$. Desde el punto de vista jurídico-político, y como ya se ha apuntado, la Constitución de 1925 estableció oficialmente la separación entre la Iglesia y Estado, garantizándose la libertad de actuación de ambas potestades en sus respectivas esferas.

La ley fundamental vigente desde 1980 regula la libertad de conciencia y de cultos en su artículo 19.6, sin más restricciones que el respeto a la moral, a las buenas costumbres y al orden público ${ }^{36}$. Este marco constitucional, junto con la ley no 19.638 , de 1999, que posibilita la constitución jurídica de iglesias y entidades religiosas, constituyen las principales referencias normativas en la materia ${ }^{37}$. Conviene advertir que precisamente la ley $\mathrm{n}^{\circ} 19.638$ ha favorecido la promulgación de diversos reglamentos que han concretado y desarrollado la cooperación entre el Estado y las confesiones religiosas, especialmente en materia de asistencia religiosa: (i) en establecimientos penitenciarios y similares: Decreto supremo $n^{\circ} 703$ del Ministerio de Justicia (Diario Oficial: 27 de septiembre de 2002); (ii) en recintos hospitalarios: Decreto supremo nº 94 del Ministerio de Salud, Subsecretaría de Redes Asistenciales (Diario Oficial: 17 de septiembre de 2008); (iii) en establecimientos de

34 "Sería muy difícil enumerar las perturbaciones introducidas en las ideas religiosas de las colonias americanas por el regalismo español. Basta saber que hombres probos, instruidos y católicos hacían de los reyes de España casi pontífices romanos (...). Con el sacrificio de la separación adquiere, por lo menos, la Iglesia la libertad que el derecho divino le otorga y que ninguna legislación puede negarle sin convertirse en tiránica”, Pastoral colectiva de los obispos de Chile sobre la separación de la Iglesia y el Estado, Santiago de Chile, 25 de septiembre de 1925 , pp. 4 y 6. Disponible en www.bcn.cl/catalogo/detalle_libro?bib=199215\&n=1

35 Para conocer datos recientes sobre la adscripción religiosa de los ciudadanos chilenos, vid. página 15 del documento "Síntesis de resultados del censo 2012", disponible en www.iab.cl/wp.../IAB/download.php?...118 03\%7Cresumencenso_2012.pdf (página consultada el 13 de mayo de 2015). En él se apunta que un 67\% de la población se declara católica y un 16\% evangélica. Además, hay porcentajes menores referidos a otras confesiones como testigos de Jehová, mormones, judaísmo, espiritualidad indígena, etc.

36 "La libertad de conciencia, la manifestación de todas las creencias y el ejercicio libre de todos los cultos que no se opongan a la moral, a las buenas costumbres o al orden público.

Las confesiones religiosas podrán erigir y conservar templos y sus dependencias bajo las condiciones de seguridad e higiene fijadas por las leyes y ordenanzas.

Las iglesias, las confesiones e instituciones religiosas de cualquier culto tendrán los derechos que otorgan y reconocen, con respecto a los bienes, las leyes actualmente en vigor. Los templos y sus dependencias, destinados exclusivamente al servicio de un culto, estarán exentos de toda clase de contribuciones”. Art. 19 n 6 de la Constitución de 1980. Disponible en http://www.camara.cl/camara/media/docs/constitucion_politica.pdf. Página consultada el 13 de mayo de 2015.

37 Ley no 19.638 de 14 de octubre de 1999, disponible en http://pjdp.minjusticia.gob.cl/media/2013/07/ Ley_19638.pdf. Página consultada el 2 de septiembre de 2015. 
las Fuerzas Armadas y de las de Orden y Seguridad Pública: Decreto supremo n 155 del Ministerio de Defensa Nacional, Subsecretaría de Guerra (Diario Oficial: 26 de mayo de 2008); y, (iv) en la Policía de Investigaciones de Chile: Orden General No 2204 de Inspectoría General (16 de septiembre de 2008) (38 $^{38}$

En materia de educación, es necesario aludir al Oficio nº 05/1007 de la División de Educación General, Ministerio de Educación (27 de noviembre de 2014), donde se aclaran algunas dudas suscitadas en torno a la aplicación del Decreto supremo n ${ }^{\circ} 924$ del Ministerio de Educación (Diario Oficial: 7 de enero de 1984), sobre clases de religión en establecimientos educacionales. Entre otros asuntos, se prescribe que los establecimientos educacionales deberán ofrecer las clases de religión como asignatura optativa, que será escogida o rechazada de acuerdo con la voluntad de los alumnos y de sus familias. Además, se recuerda que las clases de religión deben realizarse dentro del horario lectivo, ya que constituyen un sector más del plan de estudios aprobado por el Ministerio y, por lo tanto, son objeto de subvención ${ }^{39}$.

Otra consecuencia significativa de la aprobación de la ley $n^{\circ} 19.638$ fue la creación, en el año 2000, del Registro de Entidades Religiosas de Derecho Público, a través del Decreto supremo $\mathrm{n}^{\circ} 303$ del Ministerio de Justicia (Diario Oficial: 26 de mayo de 2000) ${ }^{40}$. Según el Director de la Oficina Nacional de Asuntos Religiosos de Chile, hasta el momento se han efectuado más de tres mil inscripciones de "Iglesias, Entidades Eclesiásticas y otras formas de expresión de fe trascendente" ${ }^{\prime \prime}$.

Sin embargo, conviene señalar que el principio de cooperación con las confesiones no ha sido recogido expresamente como mandato constitucional; principio que sí está consagrado en otros Estados ${ }^{42}$. Este hecho podría interpretarse, o bien como una ausencia de valoración de la esfera institucional y comunitaria de las religiones por parte de los poderes públicos; o bien como un signo de que no se considera necesaria ni oportuna su inclusión en la carta magna. Sea como fuere, la ausencia de colaboración específica podría suponer, en la práctica, un tratamiento igualitario $-y$, quizá por eso, no del todo satisfactorio- del hecho religioso en el ámbito civil.

Así, tal y como señala el profesor Salinas, "el Estado de Chile ha renunciado, de momento, a regular lo religioso teniendo en cuenta la peculiaridad de las diversas confesiones presentes en el país, y ha optado por la política de extender los beneficios de que disfruta la Iglesia católica al resto de las confesiones religiosas. Esta política, sin embargo, encuentra sus limitaciones en la diversidad objetiva que existe entre las diversas confesiones religiosas,

\footnotetext{
${ }^{38}$ Las citadas normas reglamentarias puede consultarse en http://www.celir.cl/v2/index.php?option=com_conte nt\&task=view\&id $=11 \&$ Itemid $=27$

39 Vid. Oficio $n^{\circ}$ 05/1007 de la División de Educación General, Ministerio de Educación (27 de noviembre de 2014), disponible en http://www.celir.cl/v2/index.php?option=com_content\&task=view\&id=11\&Itemid=27

${ }^{40}$ Vid. http://pjdp.minjusticia.gob.cl/media/2013/07/Dto-303.pdf. Página consultada el 2 de septiembre de 2015.

41 "Una aproximación analítica a la relevancia histórica del hecho religioso examinado desde ámbitos de la Historia del Derecho", p. 4. Texto de la conferencia dictada por Humberto Lagos Schuffeneger en el acto solemne de su incorporación como socio activo de la Sociedad Chilena de Historia y Geografía. Disponible en http:// www.onar.gob.cl/documentos/articulos/. Página consultada el 2 de septiembre de 2015.

42 Véase el caso, ya citado, del Perú; o de naciones europeas como Italia y España, a los que me referiré más adelante.
} 
las que impiden en ocasiones una total equiparación”“3 . No obstante lo anterior, cabe advertir que la ausencia de pactos podría atribuirse también a circunstancias internas de las propias confesiones, especialmente de las denominadas minoritarias, que no presentan una estructura organizativa y jurídica tan desarrollada como la que posee la Iglesia católica romana $^{44}$. Y, desde el punto de vista jurídico-político, la inexistencia de acuerdos en materia religiosa podría atribuirse a la falta de voluntad o de necesidad política para suscribirlos ${ }^{45}$.

\subsubsection{Organismos oficiales competentes en materia de cooperación con las} confesiones: la Oficina Nacional de Asuntos Religiosos (ONAR)

En Chile, a diferencia de lo que ocurre en el Perú, no existe actualmente una dirección general que se encargue de gestionar la proyección social del hecho religioso en el ámbito civil. Sin embargo, cabe destacar que en 2007 se creó la Oficina Nacional de Asuntos Religiosos (ONAR), dependiente del Ministerio Secretaría General de la Presidencia, cuyo objetivo principal es representar al Gobierno frente a las diferentes confesiones, así como la promoción y tutela del derecho de libertad religiosa garantizado en la constitución de la República. De esta manera, las organizaciones religiosas minoritarias cuentan con un órgano creado ad hoc que vela por una aplicación efectiva del principio de igualdad.

Precisamente, la ONAR tiene como visión "ser una entidad asesora del Gobierno en materias de índole religioso, que administra los programas de Ejecutivo hacia las Iglesias y garantiza con eficacia la igualdad de todas estas organizaciones ante el Estado". Y, como misión, "representar al Gobierno frente a todas las entidades religiosas de Chile, con el fin de canalizar y responder las solicitudes o inquietudes que ellas presenten, así como asesorar al Ejecutivo en materias que se relacionen con el ejercicio igualitario de la Libertad de Culto en nuestro país" ${ }^{36}$.

Parece claro que este asunto -el de la igualdad de los diferentes credos ante la leypreocupa tanto a los líderes religiosos como a los dirigentes políticos, y así se refleja en varias notas de prensa publicadas tras las reuniones que mantienen con cierta periodicidad ${ }^{47}$.

La Oficina Nacional de Asuntos Religiosos lleva a cabo actividades de diversa índole, como por ejemplo: (i) celebración de encuentros bilaterales entre representantes del Gobierno y de la confesión religiosa respectiva para abordar asuntos que interesan a ambas partes ${ }^{48}$; (ii)

43 SAlinas (2004) p. 252. Desde una óptica comparada, prosigue el Dr. Salinas: "Una mirada a nuestros vecinos nos permite ver que en la recientemente aprobada Constitución de Perú, ha quedado expresamente consignada la posibilidad de que el Estado peruano pueda suscribir acuerdos con las confesiones religiosas, con lo que Perú, en esta materia, se ha puesto a la altura de los países más avanzados”. SALINAS (2004) p. 253.

44 En efecto, la Iglesia católica posee una estructura interna y externa estable; está gobernada por un Sumo Pontífice que es su cabeza visible; y cuenta con un ordenamiento jurídico propio. Características todas ellas que la distinguen de otras confesiones religiosas.

45 Vid. Salinas (2009) pp. 514 y 532.

46 http://www.onar.gob.cl/la_onar/mision_vision/. Página consultada el 2 de septiembre de 2015.

47 Vid., en este sentido, las declaraciones de la Ministra Secretaria General de la Presidencia durante un encuentro con las iglesias de las tradiciones cristiana evangélicas en septiembre de 2014 (disponibles en http:// www.onar.gob.cl/2014/09/gobierno-realiza-encuentro-con-las-iglesias-de-las-tradiciones-cristiana-evangelicas/).

48 Vid. http://www.onar.gob.cl/2014/05/la-ministra-ximena-rincon-recibe-a-representantes-de-la-comunidadjudia-en-chile/; http:/www.onar.gob.cl/2014/05/la-ministra-ximena-rincon-recibe-a-representantes-del-centrocultural-islamico/. 
organización de cursos y de talleres de formación dirigidos a líderes religiosos, ministro de culto o profesores de religión en escuelas públicas ${ }^{49}$; (iii) apoyo de eventos dirigidos a promover la tutela de los derechos fundamentales que aparecen conectados, directa o indirectamente, con la libertad religiosa ${ }^{50}$; y (iv) participación en actos de culto o de especial significación en el calendario de las organizaciones religiosas, como el Día Nacional de las Iglesias Evangélicas, el denominado Te Deum evangélico o la fiesta de la Hannukah judía ${ }^{51}$.

Si bien la ONAR es un organismo dedicado específicamente a la tutela de la libertad religiosa, existen otras instancias que se refieren a ella de manera no exclusiva. A este respecto, destaca el Instituto Nacional de Derechos Humanos (INDH), que inició sus actividades en 2010 tras varios años de gestación ${ }^{52}$ con el objeto de promover y proteger "los derechos humanos de las personas que habiten en el territorio de Chile, establecidos en las normas constitucionales y legales; en los tratados internacionales suscritos y ratificados por Chile y que se encuentran vigentes, así como los emanados de los principios generales del derecho, reconocidos por la comunidad internacional" 53 .

No cabe duda de que la protección de la libertad religiosa se incluye entre los objetivos e intereses del INDH. Prueba de ello es la inclusión de un apartado específico dedicado a esa temática en el "Informe Anual Situación de los Derechos Humanos en Chile 2014"54 donde, toda vez presentado el status quaestionis, se destacan los avances producidos en esta materia y se mencionan casos recientes en que la tutela de la libertad religiosa ha debido ponderarse con la salvaguarda de otros derechos fundamentales ${ }^{55}$.

\footnotetext{
49 Vid. http://www.onar.gob.cl/2015/01/onar-organiza-mesa-de-dialogo-interreligioso-sobre-la-religion-en-laescuela-publica/; http://www.onar.gob.cl/2014/10/ensenanza-religiosa-en-colegios-publicos-de-chile/; http:// www.onar.gob.cl/2014/07/acreditar-formacion-religiosa/.

50 Tal es el caso de los derechos de la infancia o del diálogo para la convivencia pacífica entre los distintos credos. Vid., respectivamente: http://www.onar.gob.cl/2014/06/onar-propicia-dialogo-entre-el-consejo-nacionalde-la-infancia-y-organizaciones-religiosas-defensora/; y, http://www.onar.gob.cl/2014/05/onar-estrecha-lazoscon-red-interreligiosa-de-educacion-para-la-paz-2/.

${ }^{51}$ Vid. http://www.onar.gob.cl/2014/09/presidenta-michelle-bachelet-encabeza-te-deum-evangelico/; http:// www.onar.gob.cl/2014/10/celebracion-del-dia-nacional-de-las-iglesias-evangelicas; http://www.onar.gob. cl/2013/12/jefe-de-estado-encabeza-celebracion-de-festividad-judia-de-januca-en-la-moneda/.

52 El proyecto de Ley $n^{\circ} 20.405$ que crea el Instituto Nacional de Derechos Humanos ingresó al Congreso el día 15 de junio de 2005; sin embargo, la ley no fue promulgada hasta el 24 de noviembre de 2009 (publicación en el Diario Oficial de 10 de diciembre de 2009). El acto constitutivo del INDH tuvo lugar el 20 de julio de 2010. Vid. http://www.indh.cl/resena-institucional/historia. Página consultada el 2 de septiembre de 2015.

53 Vid. el artículo 2 de la Ley $n^{\circ}$ 20.405, disponible en http://www.indh.cl/wp-content/uploads/2010/10/ ley20405.pdf. Página consultada el 2 de septiembre de 2015.

54 Informe completo disponible en http://www.indh.cl/wp-content/uploads/2014/12/INDH-2014-Final.pdf. La sección dedicada a la libertad religiosa se encuentra en las pp. 157-167.

55 En concreto, se mencionan dos supuestos relacionados con el respeto de las festividades de carácter religioso (vid. Corte de Apelaciones de Santiago, Rol No 132.162-2013, sentencia de 2 de enero de 2014, y su revocación por la Corte Suprema, Rol No 1720-2014, sentencia de 11 de marzo de 2014; y, Corte de Apelaciones de Valparaíso, Rol No 460-2014, sentencia de 4 de abril de 2014). Además, se alude a otro recurso presentado ante los tribunales donde se pondera el derecho de no recibir educación religiosa en un centro educativo de carácter confesional (vid. Corte de Apelaciones de Valdivia, Rol No 2095-2013, sentencia de 21 de enero de 2014). El resumen de los casos citados puede verse en http://www.indh.cl/wp-content/uploads/2014/12/ INDH-2014-Final.pdf, pp. 162-164.
} 


\subsubsection{Libertad religiosa y pueblos indígenas}

En el actual contexto social y cultural es necesario aludir a la realidad de los pueblos originarios o indígenas, ya que en ellos el factor religioso cobra unos matices específicos y aparece estrechamente unido a otros elementos esenciales que integran su manera de ver e interpretar el mundo o cosmovisión; principalmente por su concepción de la madre tierra y de todo aquello que conecta con la sacralidad de los recursos y de los entornos naturales ${ }^{56}$.

La interacción de los pueblos indígenas con la naturaleza, que presenta fuertes rasgos de espiritualidad, debe de ser reconocida con sus caracteres específicos. Al menos esta ha sido la línea seguida por diversos organismos internacionales, que destacan el vínculo de las comunidades con sus territorios tradicionales, así como el indiscutible arraigo de estos en la conformación de su identidad cultural e histórica ${ }^{57}$. En definitiva: no cabe soslayar la particular relación que los individuos y las comunidades indígenas mantienen con el medio ambiente y con los territorios que habitan ${ }^{58}$.

En Chile, desde los orígenes mismos del Estado, los mapuches adoptaron una cosmovisión basada en el mantenimiento del orden del universo y de todas las cosas, que solo era posible conservar en la medida en que el actuar del hombre fuera el correcto. Así, el respeto por la naturaleza constituía la base filosófica para transformarla en un recurso que permitiera perpetuar la existencia de los pueblos ${ }^{59}$.

Aunque, hasta el momento, no exista una referencia expresa a los pueblos indígenas en la Constitución chilena ${ }^{60}$, parece claro que en los últimos años se advierte una mayor sensibilidad hacia este tema en distintos ámbitos, incluyendo el institucional ${ }^{61}$. A modo de ejemplo, puede señalarse que el "Informe Anual Situación de los Derechos Humanos en Chile 2014” incorpora una sección relativa a los derechos de los pueblos indígenas, relacionados principalmente con el respeto de sus tierras y de los recursos naturales ${ }^{62}$. Además, se alude a la tutela de la libertad religiosa de los pueblos originarios ${ }^{63}$ y se presentan resúme-

\footnotetext{
56 Vid. CASTro et al. (2009).

57 Vid. "Los Pueblos Indígenas-Tierras, Territorios y Recursos Naturales”. Documento del Foro Permanente para las Cuestiones Indígenas de las Naciones Unidas. Disponible en: http://www.un.org/esa/socdev/unpfii/ documents/6_session_factsheet1_es.pdf. Página consultada el 3 de septiembre de 2015.

58 Vid. el Proyecto de Declaración Americana sobre los derechos de los Pueblos Indígenas, especialmente los artículos VII, X, XIII y XVIII. Disponible en: http://www.cidh.org/Indigenas/Cap.2g.htm. Página consultada el 3 de septiembre de 2015.

59 Vid. "Los pueblos originarios y los recursos naturales. Filosofía, territorio e identidad en la construcción del desarrollo", disponible en http://observatoriogeograficoamericalatina.org.mx/egal12/Geografiasocioeconomica/ Geografiacultural/64.pdf pp. 4-7. Página consultada el 3 de septiembre de 2015.

60 Reconocimiento que sí existe en las constituciones de otras naciones latinoamericanas. Vid. CLAVEro (2007) p. 36.

61 Precisamente, la Corporación Nacional de Desarrollo Indígena (CONADI) tiene como misión institucional "promover, coordinar y ejecutar la acción del Estado en favor del desarrollo integral de las personas y comunidades indígenas, especialmente en lo económico, social y cultural y de impulsar su participación en la vida nacional”. http://www.conadi.gob.cl/index.php/nuestra-institucion/mision-institucional. Página consultada el 3 de septiembre de 2015 .

62 Vid. http://www.indh.cl/wp-content/uploads/2014/12/INDH-2014-Final.pdf, pp. 227-250.

63 Vid. http://bibliotecadigital.indh.cl/handle/123456789/780, pp. 164 y 165.
} 
nes ejecutivos del informe en lengua rapa nui, aymara o aimara y mapudungún o mapuzungún, respectivamente $e^{64}$.

En décadas pasadas ha habido novedades importantes en la regulación de esta materia. Además de la aprobación en 1993 de la denominada "Ley indígena" ${ }^{65}$, debe resaltarse el punto de inflexión producido en 2008, momento en que el Estado chileno ratificó el Convenio $\mathrm{n}^{\circ} 169$ sobre Pueblos Indígenas y Tribales en Países Independientes de la Organización Internacional del Trabajo (OIT), incorporándolo así a su ordenamiento jurídico ${ }^{66}$.

En el convenio se alude a la tutela del bienestar espiritual de los pueblos indígenas, que implica, entre otros, los siguientes avances: (i) reconocimiento y protección de los valores y prácticas sociales, culturales, religiosas y espirituales propias de los pueblos indígenas, tanto en su dimensión individual como en proyección colectiva ${ }^{67}$; (ii) consagración del derecho de los pueblos indígenas o tribales a autodeterminarse; es decir, a que se les reconozca la facultad para decidir por sí mismos acerca de su proceso de desarrollo, instituciones, creencias y bienestar espiritual $^{68}$; y (iii) los estados suscriptores deberán considerar la especial relevancia que las comunidades atribuyen a la cultura y a los valores espirituales relacionados con sus tierras, sobre todo en lo relativo a los diferentes modos de entender la propiedad ${ }^{69}$. Por lo demás, parece indudable que los individuos y las comunidades indígenas son cada vez más conscientes de los derechos que le son propios y de los mecanismos legales habilitados para su tutela efectiva; lo cual ha redundado en un aumento significativo de la judicialización de los conflictos en que se ven implicadas personas o grupos indígenas. La Corte Suprema se ha pronunciado ya en varias ocasiones acerca de los elementos de la cosmovisión trascendente indígena que pueden ser invocados ante los tribunales de justicia como bienes jurídicos protegibles ${ }^{70}$. Y todo apunta a que en los próximos años esta materia seguirá reclamando una atención preferente por parte de los órganos jurisdiccionales chilenos.

\footnotetext{
${ }_{64}$ Vid. http://www.indh.cl/wp-content/uploads/2014/12/INDH-2014-Final.pdf

${ }^{65}$ Ley n ${ }^{\circ} 19.253$, promulgada el 28 de septiembre de 1993 y publicada en el Diario Oficial el 5 de octubre. Disponible en http://www.conadi.gob.cl/documentos/LeyIndigena2010t.pdf. Página consultada el 3 de septiembre de 2015.

66 El convenio fue adoptado el 27 de junio de 1989 por la Conferencia General de la Organización Internacional del Trabajo y ratificado por Chile el 2 de octubre de 2008, durante el primer gobierno de Michelle Bachelet. Su texto completo puede consultarse en: http://www.mineduc.cl/usuarios/intercultural/ doc/201104071329170.Convenio_169_OIT.pdf. Página consultada el 3 de septiembre de 2015. Vid. AGUILAR (2007) p. 434.

67 Vid. art. $5 \mathrm{n}^{\circ} 1$ del Convenio ${ }^{\circ} 169$ de la OIT.

68 Vid. art. $7 \mathrm{n}^{\circ} 1$ del Convenio ${ }^{\circ} 169$ de la OIT.

${ }^{69}$ Vid. art. $13 \mathrm{n}^{\circ} 1$ del Convenio $\mathrm{n}^{\circ} 169$ de la OIT. Este procedimiento investigador de los gobiernos sobre la concepción indígena de la propiedad se ha realizado, en varias ocasiones, a través de una solicitud directa sobre el Convenio.

70 Vid. http://www.indh.cl/wp-content/uploads/2014/12/INDH-2014-Final.pdf, pp. 164 y 165; y CASTRO et al. (2009).
} 


\section{PLURALIDAD RELIGIOSA Y ACUERDOS EN EL DERECHO COMPARADO}

\subsection{Actualidad del Derecho bilateral o pacticio}

En los apartados anteriores hemos visto que tanto en Chile como en Perú los respectivos ordenamientos jurídicos han ido conformando Estados plurales que tutelan la libertad religiosa como derecho fundamental. Y ello en un contexto global de sociedades cada vez más interculturales, donde la heterogeneidad de ideologías y de creencias se proyecta sobre los mecanismos de protección de los derechos humanos, en general, y de la libertad de pensamiento, de conciencia y de religión, en particular.

También se ha puesto de relieve que, no obstante la actual secularización de las sociedades occidentales, el hecho religioso sigue ocupando un lugar importante como factor social, sin duda reconocible en su dimensión espiritual o trascendente y en su aportación cultural. De ahí que la ciencia del Derecho despliegue, también es este ámbito, diversos mecanismos armonizadores y trate de garantizar la convivencia pacífica de todos los ciudadanos y grupos sociales ${ }^{71}$.

Habida cuenta de que las normas jurídicas de naturaleza bilateral son cada vez más frecuentes en el Derecho comparado, no es irreal plantearse si Chile y Perú presentan las condiciones adecuadas para el establecimiento de nuevos cauces de cooperación jurídica e institucional en materia religiosa a través de pactos con las confesiones. De ser así, podría identificarse el contenido mínimo de un posible acuerdo entre Chile y la Santa Sede ${ }^{72}$, ya que Perú sí dispone de un instrumento concordatario vigente desde 1980. No es irrelevante señalar que la Santa Sede mantiene relaciones bilaterales con ciento setenta y nueve Estados y ha firmado acuerdos con más de cincuenta países de Europa, América Latina, Asia y África ${ }^{73}$. En los últimos años se han suscrito acuerdos concordatarios con países de tradiciones jurídicas y religiosas tan diferentes como Azerbaiyán ${ }^{74}$, Mozambique ${ }^{75}$, Palestina ${ }^{76}$ o Serbia ${ }^{77}$, entre otros.

\footnotetext{
71 "En ocasiones, el Estado dicta normas para regular el factor religioso en su dimensión social; el conjunto de normas de origen estatal dirigidas a regular en su dimensión de justicia esta natural tendencia del hombre a lo sobrenatural cuando ella se convierte en un factor social es el Derecho eclesiástico del Estado, moderna rama del derecho occidental que pretende construir sistemáticamente, conforme a unos principios informadores particulares, una rama autónoma del derecho con consistencia científica propia”. SALINAS (2009) p. 501.

72 En la actualidad Chile no tiene suscrito un Concordato con la Santa Sede; si bien ambas partes negociaron varios proyectos en la década de 1920 que, finalmente, no prosperaron. El profesor Carlos Salinas Araneda descubrió dichos proyectos concordatarios en el Archivo Secreto Vaticano, que constituyen los únicos conocidos hasta el momento en que se abordan, de manera específica, los temas en los que confluyen los intereses del Estado de Chile y de la Iglesia católica. Vid. Salinas (2012b) y Salinas (2014).

73 Vid. http://www.vatican.va/roman_curia/secretariat_state/index_concordati-accordi_sp.htm. Página consultada el 3 de septiembre de 2015

74 Acuerdo entre la Santa Sede y la República de Azerbaiyán, de 29 de abril de 2011, disponible en http://bibliotecanonica.net/docsaf/btcafm.pdf. Página consultada el 3 de septiembre de 2015.

75 Acuerdo entre la Santa Sede y la República de Mozambique, de 7 de diciembre de 2011. Vid. http://www. news.va/en/news/holy-see-and-mozambique-ratify-their-2011-agreement. Página consultada el 3 de septiembre de 2015.

76 Vid. Acuerdo entre la Santa Sede y Palestina, de 26 de junio de 2015. Vid. http://www.news.va/en/news/ signed-in-the-vaticans-apostolic-palace-comprehens. Página consultada el 3 de septiembre de 2015.

77 Vid., Acuerdo entre la Santa Sede y la República de Serbia, de 27 de junio de 2014. Vid. http://www.news. va/en/news/agreement-between-the-holy-see-and-serbia. Página consultada el 3 de septiembre de 2015.
} 
En lo que atañe a las demás confesiones religiosas, hasta el momento no se han alcanzado acuerdos ni con Perú ni con Chile, si bien ningún precepto legal impide que estos puedan celebrarse en un futuro. Además, como se ha apuntado, esta posibilidad ha sido reconocida explícitamente en la constitución peruana.

Por otro lado, es preciso tomar en consideración la diferente naturaleza jurídica de los pactos en esta materia: mientras que en el caso de la Iglesia católica tienen rango de tratado internacional -en virtud de la personalidad jurídica internacional atribuida a la Santa Sede-, los acuerdos con las demás organizaciones religiosas ostentan rango de ley ordinaria. Este hecho no tiene por qué suponer, en la práctica, un menoscabo en el reconocimiento de las prerrogativas de las confesiones no católicas. No en vano, refiriéndose a los casos particulares de Alemania e Italia, el profesor De la Hera argumenta de manera elocuente que "la posición internacional de la Iglesia católica y de la Santa Sede no es ni poseída ni pretendida por las demás confesiones, a cuya estructura no corresponde esa forma de personalidad jurídica. Que tal hecho marque una diferencia entre la calificación jurídica de los Acuerdos con la Santa Sede y los firmados posteriormente con las otras tres confesiones, es algo que carece de relevancia; los acuerdos alemanes con las confesiones evangélicas, incluso tenida en cuenta la intervención no del Estado federal sino de los Lander como Partes signatarias, así como las numerosas intese italianas, han avanzado como tales textos pacticios y como objeto de atención por parte de la doctrina hasta posiciones que tienen solventada y superada esa reserva"78.

Los asuntos que suelen incluirse en los instrumentos bilaterales entre el Estado y las diversas confesiones -Iglesia católica, Iglesias protestantes, Judaísmo o Islam, entre otrastienen que ver con la protección de las dos dimensiones en que se proyecta la libertad religiosa: la individual -o de conciencia- y la colectiva - dimensión institucional y asociativa-. Son todas ellas cuestiones de una indudable trascendencia social y deben ser abordadas atendiendo a las peculiaridades de cada específica organización religiosa.

A modo de ejemplo, en la dimensión individual cabe señalar las siguientes materias: (i) garantía de la enseñanza religiosa en los centros educativos estatales (públicos) o con financiación estatal (particulares subvencionados); (ii) asistencia religiosa en las Fuerzas Armadas y en centros o establecimientos penitenciarios, hospitalarios, asistenciales u otros análogos del sector público; (iii) reconocimiento de efectos civiles al matrimonio celebrado según la forma religiosa específica de cada confesión; y, (iv) celebración de días feriados con marcada significación religiosa.

En cuanto a los derechos colectivos, pueden señalarse los siguientes: (i) reconocimiento de la libertad de las entidades religiosas para desarrollar su misión espiritual, docente y de servicio a la sociedad; (ii) exención de determinados impuestos y cargas tributarias; (iii) incorporación de los ministros de culto al Régimen de la Seguridad Social; (iv) reconocimiento de la libertad para establecer lugares de culto y cementerios propios; (v) garantía de tutela de los asuntos relacionados con la alimentación propia; y (vi) colaboración del Estado en la conservación de los bienes patrimoniales pertenecientes a las confesiones religiosas ${ }^{79}$.

\footnotetext{
78 De la Hera (1995) p. 218.

79 Vid. http://www.pluralismoyconvivencia.es/materiales_didacticos/glosario/acuerdos_de_cooperacion.html. Página consultada el 2 de septiembre de 2015.
} 


\section{2. ¿El modelo español como referencia para Chile y Perú?}

Como ejemplos de países que han desarrollado el Derecho bilateral en materia religiosa pueden señalarse Alemania, Italia y España. A mi juicio, por evidentes razones históricas y culturales, España podría constituir una referencia válida para los Estados latinoamericanos al menos en parte de los asuntos regulados por el Derecho Eclesiástico. De hecho, es posible inferir que tanto en Perú como en Chile se tuvo en cuenta la experiencia española en el momento de crear la Dirección de Asuntos de la Iglesia Católica, la Dirección de Asuntos Interconfesionales (Perú) y la Oficina Nacional de Asuntos Religiosos (Chile), anteriormente citadas.

En España, el órgano encargado de gestionar la proyección social del factor religioso se denomina Subdirección General de Relaciones con las Confesiones, que constituye una unidad administrativa dependiente de la Dirección General de Cooperación Jurídica Internacional y Relaciones con las Confesiones. La subdirección se proyecta en tres ámbitos diferentes de actuación: gestión del Registro de Entidades Religiosas; gestión de las relaciones con las distintas confesiones religiosas; y la promoción de estudios y análisis sobre el derecho fundamental de libertad religiosa ${ }^{80}$.

El cambio de rumbo en el Derecho eclesiástico español debe entenderse en el nuevo marco político establecido por la Constitución española de 1978, que supuso un cambio sustancial respecto a las leyes fundamentales anteriores. El poder constituyente decidió evitar las soluciones extremas -confesionalidad católica material y laicismo beligerante- y diseñó un sistema garante de los derechos y libertades fundamentales donde se valoraba el hecho religioso como factor social positivo y se daba cabida a las relaciones institucionales entre el Estado y las confesiones. Con este espíritu se redactó el artículo 16 de la Constitución $^{81}$, del que se desprenden los principios informadores del ordenamiento jurídico español en materia religiosa, a saber: libertad religiosa, laicidad, igualdad y cooperación ${ }^{82}$.

En este contexto, resultan especialmente reseñables los siguientes hitos: (i) la derogación del Concordato de 1953 -suscrito con la Santa Sede durante el Régimen del General Franco- y su reemplazo por los Acuerdos Parciales de 1976 y 1979, actualmente en vigencia $^{83}$; (ii) la aprobación de la Ley Orgánica de Libertad Religiosa de 1980, que posibilitó

${ }^{80}$ Vid. http://www.mjusticia.gob.es/cs/Satellite/Portal/es/servicios-ciudadano/cartas-servicios/subdirecciongeneral5.

81 "Se garantiza la libertad ideológica, religiosa y de culto de los individuos y las comunidades sin más limitación, en sus manifestaciones, que la necesaria para el mantenimiento del orden público protegido por la ley.

Nadie podrá ser obligado a declarar sobre su ideología, religión o creencias.

Ninguna confesión tendrá carácter estatal. Los poderes públicos tendrán en cuenta las creencias religiosas de la sociedad española y mantendrán las consiguientes relaciones de cooperación con la Iglesia Católica y las demás confesiones". Artículo 16 de la Constitución española de 1978. Disponible en http://www.boe.es/diario_boe/ txt.php?id=BOE-A-1978-31229. Página consultada el 2 de septiembre de 2015.

${ }_{82}$ La doctrina científica explicitó los principios informadores del nuevo Derecho Eclesiástico, a saber: libertad religiosa, laicidad, igualdad y cooperación. Vid. VILADRICH (1980).

${ }_{83}$ El texto de los Acuerdos entre España y la Santa Sede puede consultarse en http://www.vatican.va/roman curia/secretariat_state/archivio/documents/rc_seg-st_19790103_santa-sede-spagna_sp.html. Página consultada el 2 de septiembre de 2015.

Existe abundante bibliografía sobre la materia. Sin ánimo de ser exhaustivos, se apuntan los siguientes trabajos: Fornés (1980); SÁncheZ-Lasheras (2010); SánCHEZ-Lasheras (2012); y VÁzquez (2004). 
que las confesiones diversas a la católica pudieran suscribir convenios de cooperación con los poderes públicos ${ }^{84}$; y (iii) la suscripción de acuerdos con las comunidades evangélica, judía y musulmana, en $1992^{85}$; año en el que, por primera vez en su Historia, el Estado reconocía y valoraba el aporte de dichas confesiones a la cultura y a la identidad de España, justamente cuando se cumplían cinco siglos de la unificación política y religiosa llevada a cabo por los Reyes Católicos.

Si se efectúa un análisis comparado entre España y Latinoamérica, se comprueba que en la mayoría de las constituciones de los países hispanohablantes se reconoce la laicidad del Estado, así como la libertad religiosa y el principio de igualdad. Sin embargo, en casi ninguna de ellas se contempla de manera explícita el principio de cooperación con las confesiones, exceptuando el caso de Perú ${ }^{86}$. Aunque en Chile no se reconozca formalmente como tal, algunos autores señalan que, en la práctica, sí existe una colaboración material con las confesiones religiosas ${ }^{87}$. Así, un ejemplo de cooperación fue la celebración de la "I Jornada Interreligiosa de Evaluación y Estudio de la Ley No 19.638 (Ley de Culto)”, celebrada en Santiago el 7 de mayo de 2015. El evento fue organizado conjuntamente por la Oficina Nacional de Asuntos Religiosos (ONAR), el Ministerio de Justicia y la Secretaría General de la Presidencia, y contó con la participación de académicos, representantes de diversas confesiones religiosas y funcionarios del Gobierno.

No me compete predecir si en un futuro cercano será posible y/o conveniente la creación de nuevos espacios de libertad religiosa en Chile o en el Perú, a través de la normativa pacticia. Sea como fuere, parece claro que la vigencia de acuerdos en esta materia no es, ni mucho menos, un vestigio del pasado.

A modo de síntesis, y en palabras de una destacada especialista española, "del análisis de la realidad jurídica y social del siglo XXI se deduce una conclusión que no cabe obviar; y es una indiscutida vitalidad de las religiones institucionales en el ámbito social. En efecto, la pluralidad de acuerdos y pactos a todos los niveles entre autoridades civiles y religiosas pone de relieve que, efectivamente, el fenómeno de expansión de las libertades públicas no ha llevado a eclipsar o postergar las religiones. Todo lo contrario, la globalización de la libertad condujo en un primer momento a las grandes declaraciones de derechos y, después, a específicos instrumentos de Derecho pacticio también con los grupos de origen o configuración religiosa. (...) Una forma ágil, concreta y hasta hoy eficaz, de garantizar la autenticidad y pluralidad del factor religioso ha sido, precisamente, la elaboración de con-

\footnotetext{
${ }^{84}$ Vid. Ley Orgánica 7/1980 de 5 de julio. Disponible en http://www.boe.es/boe/dias/1980/07/24/pdfs/ A16804-16805.pdf. Página consultada el 3 de septiembre de 2015.

85 Vid. las leyes 24/1992, 25/1992 y 26/1992, de 10 de noviembre de 1992, cuyos textos pueden consultarse en: http://www.mjusticia.gob.es/cs/Satellite/Portal/es/areas-tematicas/libertad-religiosa/normativa-materialibertad/legislacion-estatal. Página consultada el 3 de septiembre de 2015.

86 Sobre el reconocimiento explícito o tácito de este principio en el continente sudamericano, puede verse la completa monografía de PATiÑo (2011).

87 Vid. PATıÑo (2011) pp. 191-252. Vid. http://www.minsegpres.gob.cl/2015/05/subsecretaria-en-jornadainterreligiosa-de-evaluacion-de-ley-de-culto/. Además, ese mismo día se constituyó el Consejo Asesor Intereligioso de Chile. Vid. http://www.minsegpres.gob.cl/galeria_imagen/ministra-rincon-y-subsecretaria-silva-participan-de-la-constitucion-del-consejo-asesor-interreligios/.
} 
venios, acuerdos, pactos o, en sentido más amplio, lo que hemos venido llamando derecho pacticio" 88 .

\section{CONCLUSIONES}

1. Este artículo resume el iter histórico-jurídico de la legislación sobre el factor social religioso en Chile y en el Perú. Ambos países han transitado desde modelos confesionales católicos hacia Estados plurales que tutelan la libertad religiosa como derecho fundamental.

2. A pesar de la existencia de sociedades cada vez más secularizadas, es claro que el hecho religioso sigue desempeñando un papel relevante como factor social que se proyecta en su dimensión espiritual o trascendente y en su aportación cultural. No en vano, la incidencia de las religiones en el ámbito civil explica el desarrollo de un Derecho específico -el Derecho eclesiástico del Estado- y la presencia de organismos públicos como la Dirección de Asuntos de la Iglesia Católica y la Dirección de Asuntos Interconfesionales, en el Perú, o la Oficina Nacional de Asuntos Religiosos en Chile.

3. Se ha puesto de relieve que las normas jurídicas de naturaleza bilateral o pacticia son cada vez más frecuentes en el Derecho comparado -véanse los casos de España, Italia o Alemania-. Así, podría ocurrir que en el futuro Chile y Perú se planteen suscribir acuerdos con las confesiones religiosas, aunque en el supuesto de la religión católica ya existe un acuerdo concordatario firmado entre la Santa Sede y el Estado peruano en 1980.

4. En cuanto a su naturaleza jurídica, es preciso tener en cuenta que los convenios suscritos con la Iglesia católica tienen rango de tratado internacional, debido a que la Santa Sede goza de personalidad jurídica internacional; mientras que los acuerdos con las demás organizaciones religiosas ostentan rango de ley ordinaria. Esta diferencia no tiene por qué suponer, en la práctica, un tratamiento discriminatorio de las confesiones no católicas, habida cuenta de que el Derecho es capaz de amoldarse en aras a garantizar un tratamiento satisfactorio de realidades jurídicas diferentes. Dicho de otra manera: aunque de base, el Estado deba garantizar la igualdad de los diversos credos religiosos ante la ley, la regulación en esta materia debe incluir mecanismos de flexibilización que eviten que el celo por la igualdad devenga en un tratamiento igualitario de situaciones diferentes.

5. La confluencia en este campo de elementos metajurídicos -políticos, religiosos, sociológicos o culturales- dificulta la armonización de principios y de criterios normativos entre los países. Sea como fuere, la tutela de los derechos fundamentales en general, y de la libertad religiosa en particular seguirá demandando una atención preferente de los organismos internacionales y estatales competentes en la regulación de esta delicada e importante materia.

${ }^{88}$ Blanco (2007) pp. 173 y 175. Sobre el desarrollo del Derecho pacticio en los últimos años, vid. Blanco (2008). 


\section{BIBLIOGRAFÍA CITADA}

Aguilar Carvallo, Gonzalo (2007): Dinámica internacional de la cuestión indígena (Santiago de Chile, Editorial Librotecnia).

Clavero Salvador, Bartolomé (2007): "Reconocimiento mapuche de Chile: tratado ante constitución”, Corpus Iuris Regionis. Revista jurídica regional y subregional andina $\mathrm{N}^{\circ} 7$ : pp. 17-44.

Blanco, María (2008): Libertad religiosa, laicidad y cooperación en el derecho eclesiástico. Perspectiva actual del Derecho pacticio español (Granada, Editorial Comares).

Blanco, María (2007): "Laicidad del Estado y cooperación. El Derecho pacticio a examen", Persona y Derecho, No 56: pp. 157-175.

Carpio Sardón, Luis Andrés (1999): La libertad religiosa en el Perú (Piura, Colección jurídica de la Universidad de Piura).

Castro Lucic, Milka; Vergara Montoya, Juan [(eds.) 2009]: Jurisprudencia indígena. Cosmovisión y legislación (Santiago de Chile, Facultad de Derecho de la Universidad de Chile).

De la Hera, Alberto (1995): "Acuerdos con las confesiones religiosas minoritarias", Ius Canonicum XXXV, $N^{\circ}$ 69: pp. 201-231.

Díaz Muñoz, Oscar; Eto Cruz, Gerardo; Ferrer Ortiz, Javier [(coords.) (2014)]: El derecho fundamental de libertad religiosa: jurisprudencia y doctrina constitucional (Lima, Centro de Estudios Constitucionales, Tribunal Constitucional del Perú).

Fornés, Juan (1980): El nuevo sistema concordatario español (Los Acuerdos de 1976 y 1979) (Pamplona, Editorial EUNSA).

Frías Valenzuela, Francisco (2007): Manual de Historia de Chile desde la Prehistoria hasta el 2000 (Santiago de Chile, Editorial Zig-Zag, decimoquinta edición).

GonzÁlez SÁnchez, Marcos (2013): "Las leyes de libertad religiosa española y portuguesa y su influencia en las leyes y en algunos proyectos de ley de libertad religiosa iberoamericanos", Revista General de Derecho Canónico y Derecho Eclesiástico del Estado, No 32: pp. $1-36$.

Interdonato, Francisco (1981): "Relaciones de la Iglesia y el Estado en la nueva constitución del Perú", Revista de Derecho de la Pontificia Universidad Católica del Perú, No 35: pp. 87-95.

Mosquera, Susana (2011): "La cuestión religiosa en el Perú a propósito de la Ley $\mathrm{N}^{\circ}$ 29635”, Gaceta Constitucional, No 38: pp. 291-303.

Mosquera, Susana (2012): "La libertad religiosa en el constitucionalismo peruano", Derecho y Religión, No 7: pp. 149-188.

Núñez Poblete, Manuel [(dir.) (2010)]: Normativa Nacional e Internacional de los pueblos indígenas (Santiago de Chile, Editorial Librotecnia).

Patiño Reyes, Alberto (2011): Libertad religiosa y principio de cooperación en Latinoamérica (Ciudad de México, UNAM).

Salinas Araneda, Carlos (2004): Lecciones de Derecho Eclesiástico del Estado de Chile (Valparaíso, Ediciones Universitarias de Valparaíso). 
Salinas Araneda, Carlos (2009): "El Derecho eclesiástico del Estado de Chile al tiempo del bicentenario: logros y dificultades", Revista de Derecho de la Pontificia Universidad Católica de Valparaiso, No XXXIII: pp. 499-533.

Salinas Araneda, Carlos (2012a): "El factor religioso en las constituciones de la República de Chile”, Derecho y religión, No 7: pp. 212-241.

Salinas Araneda, Carlos (2012b): "Un primer proyecto de Concordato entre Chile y la Santa Sede en 1928”, Revista Chilena de Derecho, vol. 39 N³: pp. 665-698.

Salinas Araneda, Carlos (2014): "El tercer proyecto de Concordato entre Chile y la Santa Sede en 1928. Texto y comentarios", Revista de Derecho de la Pontificia Universidad Católica de Valparaíso, No 42: pp. 555-595.

Sánchez-Lasheras, Miguel (2010): "Un nuevo sistema concordatario: los Acuerdos de 1976 y 1979. El papel de la diplomacia vaticana y española (1972-1976)", en Ius et Iura. Escritos de Derecho Eclesiástico y de Derecho Canónico en honor del profesor Juan Fornés (Granada, Editorial Comares): pp. 1037-1046.

SÁnCHEZ-Lasheras, Miguel (2012): Las negociaciones concordatarias y la transición politica española (1972-1976). El acuerdo de 28 de julio de 1976 (Granada, Editorial Comares).

SAntos Loyola, Carlos R. (2013): "El desarrollo legislativo de la libertad religiosa en el Perú. Breves apuntes sobre algunos aspectos de la Ley No 29.635”, Derecho y religión, No 8: pp. 233-254.

VÁzquez García-Peñuela, José María (2004): "Examen de las relaciones entre la Santa Sede y el Estado Español: desde el Concordato de 1953 a los Acuerdos de 1979", Cuadernos de Derecho Judicial, No XI: pp. 91-116.

Viladrich, Pedro Juan (1980): "Los principios informadores del Derecho eclesiástico español”, en VV. AA., Derecho Eclesiástico del Estado español (Pamplona, Editorial EUNSA) pp. $211-316$.

\section{NORMAS CITADAS}

República del Perú:

Acuerdo entre la Santa Sede y Perú, de 26 de julio de 1980.

Constituciones Políticas de la República del Perú (1823-1993).

Decreto Supremo No 026-2002-JUS, modifica el Reglamento de Organización de Funciones del Ministerio de Justicia.

Decreto Supremo No 010-2011-JUS, aprueba Reglamento de desarrollo de la Ley No 29635.

Ley $N^{\circ} 29635$ de 20 de diciembre de 2010, Ley de Libertad Religiosa.

\section{República de Chile:}

Constituciones Políticas de la República de Chile (1818-1980)

Convenio $N^{\circ} 169$ sobre Pueblos Indígenas y Tribales en Países Independientes de la Organización Internacional del Trabajo (OIT), ratificado por Chile el 2 de octubre de 2008.

Ley No 19.638 de 14 de octubre de 1999, establece normas sobre la constitución jurídica de las iglesias y organizaciones religiosas. 
REINO DE ESPAÑA:

Ley 24/1992, aprueba Acuerdo de cooperación del Estado español con la Federación de Entidades Religiosas Evangélicas de España.

Ley 25/1992, aprueba Acuerdo de cooperación del Estado con la Federación de Comunidades Israelitas de España.

Ley 26/1992, aprueba Acuerdo de cooperación del Estado con la Comisión Islámica de España.

Acuerdos entre el Estado español y la Santa Sede de 28 de julio de 1976 y de 3 de enero de 1979.

Constitución española, publicada en el Boletín Oficial del Estado (BOE) el 29 de diciembre de 1978

Ley Orgánica 7/1980 de 5 de julio, de Libertad Religiosa.

\section{OTRAS NORMAS Y DOCUMENTOS:}

Cartas de Servicios de la Subdirección General de Relaciones con las Confesiones (Ministerio de Justicia, Gobierno de España).

Conferencia de Humberto Lagos Schuffeneger titulada "Una aproximación analítica a la relevancia histórica del hecho religioso examinado desde ámbitos de la Historia del Derecho", impartida en la Sociedad Chilena de Historia y Geografía en mayo de 2014.

Conferencia de Tarcisio Bertone titulada "La Iglesia y el Estado a doscientos años de la Independencia nacional. Historia y perspectiva”, impartida en la Pontificia Universidad Católica de Chile en abril de 2010.

Declaración Dignitatis Humanae del Concilio Vaticano II, diciembre de 1965.

Documento "Los Pueblos Indígenas - Tierras, Territorios y Recursos Naturales" del Foro Permanente para las Cuestiones Indígenas de las Naciones Unidas, agosto de 2008.

Documento "Pastoral colectiva de los obispos de Chile sobre la separación de la Iglesia y el Estado", Santiago de Chile, septiembre de 1925.

Documento "Síntesis de resultados del censo 2012".

Proyecto de Declaración Americana sobre los derechos de los Pueblos Indígenas (Comisión Interamericana de Derechos Humanos), febrero de 1997.

\section{SITIOS ELECTRÓNICOS}

http://www.iab.cl/wp-content/files_mf7resumencenso_2012.pdf

http://www.indh.cl/wp-content/uploads/2014/12/INDH-2014-Final.pdf

http://www.bcn.cl/catalogo/detalle_libro?bib=199215\&n=1

http://www.bcn.cl/

http://www.boe.es/diario_boe/txt.php?id=BOE-A-1978-31229

http://www.boe.es/boe/dias/1980/07/24/pdfs/A16804-16805.pdf.

http://www.camara.cl/camara/media/docs/constitucion_politica.pdf.

http://www.cidh.org/Indigenas/Cap.2g.htm.

http://www.congreso.gob.pe/ntley/Constitucion.asp 
http://documentos.iglesia.cl/conf/doc_pdf.php?mod=documentos_sini\&id=3978

http://www.iab.cl/wp.../AAB/download.php?...11803\%7Cresumencenso_2012

http://www.leychile.cl/Navegar?idNorma $=145268$

http://www.leychile.cl/ N?i=169459\&f=2000-05-26\&p=

http://www2.minedu.gob.pe/digesutp/formacioninicial/wpdescargas/normatividad/ley/

Ley_N_29635_libertad_religiosa.pdf

http://www.mineduc.cl/usuarios/intercultural/doc/201104071329170.Convenio_169_

OIT.pdf

http://www.minjus.gob.pe/wp-content/uploads/2014/03/DS-010-2011-JUS REGLAMENTO.pd

http://www.minsegpres.gob.cl/2015/05/subsecretaria-en-jornada-interreligiosa-de-evaluacion-de-ley-de-culto/

http://www.minsegpres.gob.cl/galeria_imagen/ministra-rincon-y-subsecretaria-silva-participan-de-laconstitucion-del-consejo-asesor-interreligios

http:/www.mjusticia.gob.es/cs/Satellite/Portal/es/areas-tematicas/libertad-religiosa/normativa-materia-libertad/legislacion-estatal

http://www.mjusticia.gob.es/cs/Satellite/Portal/es/servicios-ciudadano/cartas-servicios/ subdireccion-general5

http://observatoriogeograficoamericalatina.org.mx/egal12/Geografiasocioeconomica/Geografiacultural/64.pdf

http://www.onar.gob.cl/documentos/articulos/

http://www.onar.gob.cl/la_onar/mision_vision/.

http://www.onar.gob.cl/2013/12/jefe-de-estado-encabeza-celebracion-de-festividad-judiade-januca-en-la-moneda/.

http://www.onar.gob.cl/2014/05/la-ministra-ximena-rincon-recibe-a-representantes-de-lacomunidad-judia-en-chile/

http://www.onar.gob.cl/2014/05/la-ministra-ximena-rincon-recibe-a-representantes-delcentro-cultural-islamico/

http://www.onar.gob.cl/2014/05/onar-estrecha-lazos-con-red-interreligiosa-de-educacionpara-la-paz-2/

http://www.onar.gob.cl/2014/06/onar-propicia-dialogo-entre-el-consejo-nacional-de-lainfancia-y-organizaciones-religiosas-defensora/

http://www.onar.gob.cl/2014/07/acreditar-formacion-religiosa/.

http://www.onar.gob.cl/2014/09/gobierno-realiza-encuentro-con-las-iglesias-de-las-tradiciones-cristiana-evangelicas

http://www.onar.gob.cl/2014/09/presidenta-michelle-bachelet-encabeza-te-deum-evangelico/ http://www.onar.gob.cl/2014/10/ensenanza-religiosa-en-colegios-publicos-de-chile/ http://www.onar.gob.cl/2014/10/celebracion-del-dia-nacional-de-las-iglesias-evangelicas http://www.onar.gob.cl/2015/01/onar-organiza-mesa-de-dialogo-interreligioso-sobre-lareligion-en-la-escuela-publica/

http://www.pluralismoyconvivencia.es/materiales_didacticos/glosario/acuerdos_de_cooperacion.html.

http://sistemas3.minjus.gob.pe/asuntos-iglesia/informacion 
http://sistemas3.minjus.gob.pe/asuntos-inter.

http://sistemas3.minjus.gob.pe/asuntos-iglesia/funciones.

http://sistemas3.minjus.gob.pe/direccion-nacional-de-justicia

http://sistemas3.minjus.gob.pe/transparencia/ROF\%20MINJUS.pdf.

http://www.un.org/esa/socdev/unpfii/documents/6_session_factsheet1_es.pdf

http://www.vatican.va/archive/hist_councils/ii_vatican_council/documents/vat-ii_ decl_19651207_dignitatis-humanae_sp.html

http://www.vatican.va/roman_curia/secretariat_state/index_concordati-accordi_sp.htm

http://www.vatican.va/roman_curia/secretariat_state/archivio/documents/rc_segst_19800726_santa-sede-peru_sp.html.

http://www.vatican.va/roman_curia/secretariat_state/archivio/documents/rc_segst_19790103_santa-sede-spagna_sp.html 